\title{
Benign Frontal Sinus Neoplasm
}

National Cancer Institute

\section{Source}

National Cancer Institute. Benign Frontal Sinus Neoplasm. NCI Thesaurus. Code C4420.

A non-metastasizing neoplasm that arises from the frontal sinus. 